\title{
EL ZOPILOTE, EL TLACUACHE Y EL JAGUAR TAMBIÉN VUELAN Y CAMINAN POR LOS ANDES
}

\author{
THE ZOPILOTE, THE TLACUACHE AND THE JAGUAR ALSO \\ FLY AND WALK BY THE ANDES
}

\author{
Luis Millones Santa Gadea*
}

\begin{abstract}
Este trabajo se inserta al interior de los estudios de religión comparada de las sociedades mesoamericanas y andinas. Una constante universal es la divinización de determinados animales o sus atributos (físicos o de conducta) para crear la imagen de las deidades. En este caso nos interesa mostrar cómo son percibidos tres animales que pertenecen a la fauna de ambas civilizaciones. Todos ellos tienen valencias sagradas, pero su sentido y función son específicos a cada uno de sus ámbitos culturales.

Palabras claves: Estudios de religión comparada, sociedades mesoamericanas, sociedades andinas, divinidades, animales sagrados.

This work makes a contribution to comparative religion studies of Mesoamerican and Andean societies. A universal constant is the deification of certain animals and their attributes (physical or behavioral) in the image of the deities. Here, we highlight how three animals are perceived as belonging to the fauna of both civilizations. They all have sacred roots, but their meaning and function are specific to each of their cultural backgrounds.
\end{abstract}

Key words: Religious Studies, Mesoamerican societies, Andean societies, deities, sacred animals.

\section{Introducción}

Divinizar determinados animales es una constante en la sociedad humana. Al hacerlo, desde tiempos remotos se revivían las ansiedades de los primitivos cazadores y recolectores, que para alimentarse o para escapar de servir de alimento debieron lidiar con seres que eran más rápidos que los humanos, nadaban mejor que ellos, podían disfrazar su presencia debajo de la tierra o mimetizarse con el ambiente, y más aún, podían volar por los aires.

Superar esos inconvenientes, o al menos lograr equilibrarlos con su inteligencia, no restó la admiración por tales capacidades, y si bien el desarrollo de la agricultura y la sedentarización hizo posible un mejor control del medio geográfico, la caza no perdió su atractivo, incluso después de que se logró la domesticación de animales que le proporcionarían carne y pieles, sin necesidad de las zozobras de una aventura riesgosa.

La urbanización llegó aparejada con la diferenciación de jerarquías sociales y tanto en Mesoamérica como en los Andes la construcción de grandes palacios y templos grandiosos fue un beneficio exclusivo para las élites, y un fatigoso trabajo para los runas o maceguales. Lo interesante es que la clase dominante necesitó elementos del cuerpo de los animales: piel del puma o del jaguar, por ejemplo, seleccionados desde épocas pasadas, para dar sentido a su autoridad. Que esto fuera así se explica desde la construcción de los mitos de origen del mundo, hasta los mitos que legalizan a las dinastías reinantes. Los gobernantes explican su poder con vestimentas, adornos, colores, pinturas, edificios, etc., que son comprensibles para todos, y que con frecuencia evocan de una forma u otra a la fauna que ya podemos calificar de sagrada.

En el siglo XVI, con la invasión europea, las huestes de Cortés y Pizarro interrumpieron esta categoría de símbolos, porque el cristianismo proclamaba que la divinidad se manifestaba en forma humana. Aunque no dejaron de existir animales con presencia simbólica dentro de su doctrina, tal es el caso del león como emblema directo de la persona de Cristo o bien como Cristo resucitado (Charbonneau-Lassay 1997: 37 y 43). También el cordero, la más conocida imagen de Cristo, que se menciona muchas veces en el Apocalipsis, o la paloma como emblema del Espíritu Santo.

Para los evangelizadores (dominicos o franciscanos), que acompañaron las primeras expediciones al Cuzco o a Tenochtitlan, las figuras de animales en

\footnotetext{
* Universidad Mayor de San Marcos, Lima, Perú. Correo electrónico: 1m101@ nyu.edu
} 
las representaciones mayas o mexicas, o mochicas e incas fueron interpretadas como expresiones del demonio, que estaba posesionado de América, a pesar de que había la sospecha de una predicación cristiana previa al viaje de Colón.

Naturalmente la selección que habían realizado las civilizaciones indígenas de animales divinos, sus atributos y símbolos tenían historias culturales diferentes. La ocupación de ambos subcontinentes se supone que sucedió en un tiempo que se calcula hace alrededor de 13.000 años, aunque el debate sobre las fechas sigue encendido. De todas maneras, para Mesoamérica el desarrollo de las primeras aldeas que dejaba atrás la caza y recolección trashumante y conocía la cerámica está fechada en 2500 a.C. En los Andes se calcula que este proceso se inicia hacia 1800 a.C. Mucho antes se había logrado la domesticación de plantas y animales, y algunas de sus construcciones ceremoniales ya tenían carácter monumental.

La evolución de las aldeas en razón de su crecimiento poblacional generó la ocupación de terrenos que por razones de agotamiento, o por codicia de los vecinos, dio lugar a conflictos que determinaron la supremacía de aquellos grupos humanos que prevalecieron en la lucha por espacios agrícolas, vías de comunicación acuática, cotos de caza o recolección, etc. El tránsito del empleo de los instrumentos de caza como armas de combate pudo ser un elemento más para la adopción de determinados animales como emblemas de una sociedad o como personalidades divinas, que a la manera de patrones sagrados les podían favorecer en las contiendas.

Lo escrito hasta el momento nos haría pensar que salvo diferencias en elección de animales sagrados, la comparación de este tema de lo sobrenatural no tiene dificultades. No es así. La construcción de las religiones mesoamericanas y su desarrollo, su fase de imperial, y posteriormente su supervivencia colonial y actual, es muy diferente a las religiones andinas. Existen "dos notables características de los dioses mesoamericanos: son fisibles y fusibles. En efecto, un dios puede dividirse, separando sus atributos, para dar lugar a dos o más dioses diferentes, en ocasiones hasta opuestos. El Dios Supremo se divide inicialmente en dos para formar al Padre y a la Madre, y de ellos descenderán todas las demás divinidades; el dios de la lluvia se divide en cuatro partes, para ocupar cada uno de los rincones de la tierra; lo mismo hace el dios del fuego. En sentido contrario, varios dioses pueden fundirse para formar una sola divinidad, como son el Dios Nueve o el Dios Trece de los mayas. Además de estas propiedades, los dioses pueden fragmentarse y ocupar dos o más sitios diferentes, incluso multiplicando su presencia sobre la tierra, y cada uno de estos fragmentos está en comunicación con el resto y puede retornarse a su fuente" (López Austin y Millones 2008: 50).

Nada de lo dicho parece ser cierto en el mundo andino, aunque de tanto en tanto asoman fragmentos de lo que pudo ser una situación parecida. Es el caso de lo narrado por el documento de Huarochirí: "Como Pariacaca nació cinco halcones y después tornó en personas y cómo estando ya vencedor de todos los yuncas de Anchicocha empezó a caminar al dicho Pariacaca y lo que sucedió por el camino" (Ávila 2007: 39). El relato se complica desde el capítulo anterior, donde el redactor anónimo nos anuncia que "el denominado Pariacaca nació de cinco huevos en el sitio llamado Condorcoto" (Ávila 2007: 27).

Pero el total del relato de las crónicas no apoya esta multiplicidad de expresiones divinas de un solo personaje. En general los dioses son representados como las realidades naturales en que se creía que se manifestaban, formas a las que se les agregan notorios rasgos humanos. Por lo menos, así lo explican los españoles o indígenas letrados en la primera mirada al imperio de los incas: "[En el] altar mayor tenían puesta la figura del Sol, hecha de una plancha que cubría las paredes. La figura estaba hecha con su rostro redondo y con sus rayos y llamas de fuego todo en una pieza, ni más ni menos que la pintan los pintores" (Garcilaso 1985: 163). El mismo cronista nos describe al dios Viracocha, que de acuerdo con su relato: "Era un hombre de buena estatua, con una barba larga de más de un palmo, los vestidos largos y anchos como túnica o sotana, llegaban hasta los pies. Tenía un extraño animal, de figura no conocida, con garras de león [es decir, puma] atado por el pescuezo con una cadena, y el ramal de ella en la una mano de la estatua" (Garcilaso 1985: 259).

No siempre concuerdan los cronistas respecto de la representación antropomorfa o naturalista de animales y dioses, pero es una clara tendencia que parece desprenderse de su propia concepción cristiana, derivada de la iconografía grecolatina.

En desacuerdo con los cronistas, las sociedades anteriores a los incas muestran en sus monumentos, pinturas y esculturas, universos de representación que luchamos por entender y que quizá no fueran 
tan diferentes de la concepción que alumbró a sus contemporáneos en Mesoamérica.

\section{Animales sagrados}

Los límites de este artículo nos obligan a buscar ejemplos concretos en los que arbitrariamente elegiremos algunos animales, sin necesariamente privilegiar a los que pudieron ser más importantes para las sociedades de los dos subcontinentes. A nosotros nos preocupó hallar una fórmula que permitiese la suficiente documentación (arqueológica, histórica o etnográfica) para encontrar seres de funciones equivalentes en ambos mundos. Hay que considerar que la fauna no es necesariamente la misma, y que cada sociedad tiene historias culturales muy diferentes, en espacios geográficos aún más distintos, y por tanto percibió a los animales con miradas disímiles. Empezaremos con el Coragyps atratus (1), zopilote para los mesoamericanos y gallinazo negro para los andinos.

El zopilote tiene presencia importante en el Popol Vuh, el libro sagrado de los mayas. Cuando los gemelos sobrenaturales Hunahpú y Ixbalanqué se enfrentaron a los dioses de Xibalbá, una de las pruebas fue estar encerrados en la Casa de los Murciélagos. En un descuido, Hunahpú asomó la cabeza fuera de la cerbatana donde se había refugiado y Camazotz ["un gran animal cuyos instrumentos de matar eran como una punta seca"] lo decapitó. Ixbalanqué pidió ayuda a todos los animales para continuar la contienda (juego de la pelota) contra Xibalbá, para ello se decidió crear la ficción de que Hunahpú no había sido degollado, con este propósito la tortuga tomó la forma de la cabeza, en la que le fueron labrados los ojos. No fue una tarea fácil y porque debía reanudarse el juego al amanecer, cuando aún no concluían la cabellera y faltaba darle la capacidad de hablar. Pidieron entonces auxilio al zopilote: "Oscurece de nuevo, viejo", le dijeron. "Está bien, contestó el viejo" ["los quichés llaman al zopilote macho mama cuch, o sea, zopilote viejo"]. Y al instante oscureció (Recinos 2009: 90 173). La versión de Recinos ha sido cuestionada por otros autores (ver Tedlock, por ejemplo 1996: 127), en los que el ser que prolonga la noche y favorece a los gemelos es el tlacuache, tema del que nos ocuparemos a continuación. La relación de este ser sobrenatural con el amanecer nos sugiere López Austin (comunicación personal) inclinaría la balanza en dirección a nuestro marsupial, tanto más si en el reciente trabajo de Craveri (2013: 114-115) el pasaje en cuestión ha sido traducido así: "Tizna, viejo. Le fue dicho al tlacuache. ¡Sí! Dijo el viejo, cuando tiznó. Así, pues, entonces se oscureció cuatro veces. Tizna el tlacuache dice la gente de hoy".

El juego de la pelota se renaudó y luego de una larga serie de aventuras los seres de Xibalbá fueron derrotados y eliminados por los gemelos.

El zopilote reaparece con frecuencia en momentos importantes de la historia cultural, incluso en versiones ya cristianizadas o con alguna influencia occidental. Un relato de los mixes (noroeste de Oaxaca y sierra norte de Guerrero) nos dice que María quedó preñada por un pajarito al que ella había golpeado por defecar en su telar. Arrepentida por ello, lo cobijó bajo su camisa, el pajarito que parecía muerto revivió, y luego de revolotear bajo sus ropas huyó volando, dejándola preñada. María murió poco después al caer de un columpio, pero el zopilote rey (Sarcoramphus papa) desgarró su vientre y nacieron dos mellizos, varón y hembra. Los niños, tras aventuras propias, se convirtieron al fin en el Sol y la Luna (López Austin y Millones 2008:78).

La versión andina del Coragyps atratus es menos favorable en su relación con los humanos. La arqueología ya nos ofrece un acercamiento a esta fauna considerada siniestra, en el sitio arqueológico de Pacatnamú (distrito de Jequetepeque, provincia de Pacasmayo, departamento de La Libertad). El lugar tiene dos etapas de ocupación, la primera va del 600 al 900 d.C., que correspondería a Moche $\mathrm{V}$ en términos cronológicos. Una segunda etapa podría ser fechada entre 1100 o 1150 y 1370 d.C., bajo la autoridad de los señores de Chimor o Chimú (Donnan 1986: 22).

Los restos detectados en el sitio sugieren que dos gallinazos han picoteado y se han alimentado con víctimas humanas. Para determinar la especie de los agresores, el autor fundamenta su análisis distinguiendo los patrones de comportamiento del Coragyps atratus o gallinazo negro, del Cathartes aura o gallinazo de cabeza roja, ambos de visible presencia a lo largo de la costa peruana en espacios rurales y urbanos. De acuerdo con Rea (1986: 142), el Cathartes aura es más bien tímido y no se acercaría a un cuerpo o restos que mostrasen algún signo de vida. Por el contrario, el gallinazo negro no teme la presencia humana y es frecuente hurgador de basura y basureros públicos, aun rodeado de 
personas que transitan cerca de él. Además, cuando se alimenta de algún cadáver es notoria la preferencia por picotear en primer lugar los ojos y los genitales. Esta conducta ya ha sido documentada en la iconografía moche (Donnan 1978: 90-91), que muestra cautivos atados para ser sacrificados por gallinazos, que eran mantenidos para realizar tan brutal castigo.

Tal tipo de tortura y muerte no fue exclusiva de la sociedad mochica. Siglos más tarde, los incas fueron recordados por Phelipe Guaman Poma de Ayala en una de sus peores formas de castigo: las cárceles que denomina zancay. El dibujo es realmente tenebroso y lo explica diciendo que está "debajo de la tierra hecho bóveda muy escura" en la que figuran el grupo de animales capaz de hacer daño y atemorizar al hombre. Entre ellos, dibujado y mencionado en la lista está el que llama "buitre", que nos transmite un dibujo en el que el ave, posado sobre la cabeza de la víctima, le picotea los ojos. Esa conducta y el propio dibujo nos dicen que el sulluntuy (gallinazo en quechua) también mostró sus perfiles de verdugo en el período incaico que cronológicamente podemos ubicar entre 1300 y 1532 (Guaman Poma 1980: I, 277). Años después, el cronista Pedro Pizarro escribió hacia 1571 que "las gallinazas son como milanos, negros, tienen las cabezas peladas y coloradas (se refiere probablemente al Cathartes aura). Son sucias: comen cosas muertas. Por maravilla se les halla donde crían" (Pizarro 1978: 246).

Pero es mucho más interesante cuando el cronista nos relata lo que vio a su paso por el complejo religioso de Pachacamac, que habiendo tenido una larga historia como oráculo y centro de peregrinación en la costa central, fue adoptado por los incas. Pedro Pizarro recuerda que "al ídolo de Pachacamac tenían por costumbre, cada día, de echar muchas cargas de sardinas, pequeñas, como anchovetas frescas, en una plaza que estaba delante del ídolo. Echaban estas sardinas para que comiesen estas gallinazas... porque decían se lo mandaba así su ídolo" (Pizarro 1978: 246). Hasta el momento no tenemos evidencias arqueológicas que corroboren la presencia de gallinazos con cierto nivel de domesticación en el sitio de Pachacamac. Incluso en lo que ahora se conoce como Templo Pintado, donde se presume que estaba el santuario del dios o en sus alrededores, no hay evidencias semejantes a Pacatnamú.

Cualquiera que sea la forma en que examinemos la percepción del gallinazo andino, encontramos que ha sido confinado al espacio de los males que pueden trastornar la vida de los humanos. Incluso el cronista indígena Joan de Santa Cruz Pachacuti Yamqui Salcamaygua, que escribió hacia 1620, ya nos da indicios de que la presencia del ave invocaba una sensación de desventura: en su nido habían "guacanques" (1993: 213). Se trata de "unas yerbas o chinitas [piedras pequeñas] señaladas de la naturaleza, o otras cosas así, con que engañan los hechiceros y los dan por hechizos de amores" (González Holguín 1989: 166).

El ave negra no ha podido desprenderse de esta aura de desventura, en Cajamarca, en la sierra norteña peruana "cuando el gallinazo se despulga y sacude las alas anuncia de que va a granizar" (Ibérico s/f 89). Pero su presencia se hace más amenazante cuando aparece en los sueños: "es el aviso de que un enemigo mortal está tramando algún mal" (Ibérico s/f 93), o peor aún si en lugar de tropezarnos con el ave se trata de una bruja, seres demoníacos que suelen esconderse bajo su plumaje (Ibérico s/f 97).

Por el contrario, el zopilote, por encima del juicio desfavorable de los cronistas, nos parece un ser que transita por los muchos mundos que componen la cosmovisión mesoamericana. No importa que el cronista Diego de Landa los despreciara al descubrirlos en el país maya tratándolos de "aves muy carniceras que llaman los españoles auras y los indios kuch, estas son negras y tienen el pescuezo y cabeza como las gallinas de allá, y el pico larguillo con un garabato. Son muy sucias, pues siempre andan en los establos y en lugares de purgación del vientre comiéndola y buscando carnes muertas para comer" (Landa 2002: 193).

Luego de decir todo esto, repara que por encima de toda su repulsión está tratando de entender a un ser sobrenatural, y agrega: "Es cosa averiguada no habérseles hasta ahora conocido nido ni saber donde crían, por lo que, dicen algunos, viven vidas de doscientos años y más, y otros creen ser verdaderos cuervos" (op. cit: 194).

Esta contradicción en el cronista español en cierta forma refleja la doble percepción que también puede registrarse en los pueblos mayas. Una versión nos recuerda que el zopilote era un ave muy bella con penacho de plumas azules y amarillas, pero los dioses le ordenaron subir hasta el Sol. Sin embargo, por glotón no pudo ascender al ámbito celeste, por ello, el Sol quemó su plumas y se volvieron negras. Igualmente fue condenado a comer carroña y a volar bajo (Limón y Battock 2013: 165). Otra versión 
también maya relata que la Luna abandonó a su esposo el Sol para irse con el rey de los zopilotes (Limón y Battock 2013: 166).

Este juego con los dioses de quien no es parte de su plana mayor, pero que recurre al ingenio para lidiar con ellos, tiene un excelente ejemplo en el zopilote mesoamericano. Hay un largo relato entre los huicholes (Sierra Madre Occidental de México, estados de Jalisco y Nayarit) que nos dice que "el zopilote ayudó a escapar al venado que había sido herido por los dioses de la lluvia, por lo que estos lo amarraron y castigaron: le atravesaron una flecha en el pico; por esto tiene un orificio en él. El venado se murió pero el zopilote se desató y lo revivió". (Limón y Battock 2013: 166).

Para terminar este rapidísimo recuento de la importancia del ave en la cosmovisión mesoamericana, hay que citar la percepción desarrollada entre los otomíes (que habitan en su mayoría en los estados de Hidalgo, México y Querétaro). La personalidad femenina de la divinidad, como elemento patógeno, sucio y frío es contrapuesta al principio masculino representado por el zopilote solar, padre caliente que purifica al mundo al ser comedor de inmundicias (Galinier 1990:544).

Esta ambivalencia en la percepción del gallinazo también está presente en los Andes. En el manuscrito de Huarochirí, al describir la bóveda celeste, no olvida a "tres estrellas que brillan casi juntas. A ellas les llama cóndor, y a otras les dan el nombre del Gallinazo y de Halcón. Y cuando las Cabrillas [Pléyades, en quechua collca] aparecen de gran tamaño, dicen: este año vamos a tener maduración excelente de los frutos, pero cuando se presentan muy pequeñitas, dicen: vamos a sufrir" (Ávila 2007: 153-54). También están relacionadas con la cosecha, su ausencia en el cielo corresponde con el tiempo que media entre recoger los frutos de la tierra y volver a sembrar.

Después del despectivo tono con que los andinos se han referido al gallinazo no deja de causar sorpresa que en su libro sagrado aparezca compartiendo un espacio estelar con dos aves de reconocido prestigio en la mitología andina. Una búsqueda más detallada nos dará mayores evidencias de su ubicuidad sagrada.

La doble percepción del zopilote y del gallinazo hace que sus carnes y otras partes de su cuerpo tengan una variada aplicación en la medicina popular que va desde comerlo para curar enfermedades mentales o evitar hacerlo para no caer en la locura. Benefactor y siniestro, es un ave imprescindible en el universo sobrenatural de Perú y México.

$\mathrm{Al}$ contrario del gallinazo, al que los limeños estamos acostumbrados a ver muy cerca o al menos divisar en el cielo con mucha frecuencia, la muca, paqlla, zarigüella o qarachupa (Didelphis marsupialis) solo puede encontrarse, y no de manera fácil, en los espacios rurales mexicanos o peruanos. La qarachupa (del quechua $=$ cola pelada o calata) o el tlacuache es un sobreviviente de los marsupiales que han quedado en América luego que América del Sur se separó de África en épocas cenozoicas (o Terciaria, hace 65,5 millones de años).

El tlacuache o qarachupa es un Didélfido (dos úteros y dos vaginas) que tiene una bolsa o marsupio, que puede ser bien desarrollada o apenas un pliegue de piel, donde protege a sus crías y que cobija las mamas con que los alimenta. Nacen estas en camadas de diez o más, casi ciegas, que culminan su gestación fuera del vientre de su madre. A pesar de su aspecto tan peculiar en las descripciones folclóricas, se le suele confundir con la comadreja y con el armadillo, e incluso con el zorro. Aunque una revisión más cuidadosa nos llevará a conocer la intensidad de este personaje en el mundo sobrenatural de ambos continentes.

La intervención mítica más importante del tlacuache "nos remite a los tiempos en los que la humanidad carecía de fuego, y este era poseído por seres celestes en algunos casos, por habitantes del inframundo en otros. La "vieja avara" es uno de los dueños [del fuego] más mencionados; pero en una bella versión recogida entre los chatinos (pueblo indígena al sureste del estado de Oaxaca) son los demonios los que tienen el fuego, la fiesta, el mezcal y el tabaco. El tlacuache comisionado u oficiosamente, va con engaños hasta la hoguera y roba el fuego, ya encendiendo su cola, que a partir de entonces quedará pelada, ya escondiendo la brasa en el marsupio. Gran benefactor, el tlacuache reparte su tesoro a los hombres. Sin embargo, el mito no siempre concluye con el don del fuego. Entre los coras (grupo étnico mexicano que vive en el municipio de El Nayar, al noreste del estado de Nayarit), por ejemplo, el mundo se enciende cuando recibe el fuego, y la Tierra lo apaga con su propia leche. Entre los huicholes (estado de Jalisco y Nayarit), el héroe civilizador es hecho pedazos, pero se recompone uniendo sus partes y resucita (López Austin 1990: 21-22). 
Si bien lo dicho bastaría para dar al tlacuache un lugar en la corte divina, nuestro personaje tiene múltiples valencias sobrenaturales. En el Popol Vuh es miembro de la pareja creadora de los quichés: se trata de Hunahpú-vuch, es decir, la Abuela, la potencia femenina, dios del amanecer, asociada al jade, el grabado, la tierra, el incienso, el frijol y el pecarí. No debemos olvidar que los cuatro tlacuaches-bababoob son las cuatro columnas que se encuentran en los cuatro extremos de la tierra que sostienen el cielo, equidistantes del árbol de la ceiba que está en el centro. También está relacionado con el complejo mítico lunar, característica que es similar a la qarachupa andina. Finalmente, el tlacuache es el ladrón que fraguó el robo del maíz que luego pintó de amarillo y negro para que "la dueña del fuego" no lo reconociera (López Austin 1990: 310-312).

No menos vasto es el universo de la qarachupa. Su imagen ha sido descubierta como altorrelieve en el sitio de Ventarrón (distrito de Pomalca, provincia de Chiclayo, departamento de Lambayeque), al que se le adjudica una antigüedad de 2000 o 2500 años antes de Cristo (Alva Meneses 2012: 18 y 122). También podemos sugerir que es posible distinguir a nuestro personaje en varios de los petroglifos de Cerro Mulato (distrito de Chongoyape, provincia de Chiclayo, departamento de Lambayeque) (Núñez Jiménez 1986: 130, 141, 155) y con mayor certeza en el ángulo inferior izquierdo del Complejo II, de la Huaca Cao Viejo (distrito Magdalena de Cao, provincia de Ascope, departamento de La Libertad). Lo dicho certifica la antigüedad con que cuenta la consideración que se tiene a la qarachupa, en la actualidad la tradición oral ha retenido o renovado esta veneración y se le reconoce su condición sobrenatural, especialmente en su relación con la Luna, hay testimonios (distrito de la Merced, provincia de Aija, departamento de Ancash) repetidos en los que parados en dos patas y tomados de las "manos", las qarachupas bailan a la luz de la Luna (Marcos Yauri, comunicación personal).

A esta capacidad se le agrega la facultad de burlar la fuerza de enemigos poderosos, como el jaguar, en los inevitables encuentros en la Amazonía. Uno de los relatos más populares, el felino le pide a nuestro personaje que le entregue los shitaris (peces, también llamados carachamas) que estaba pescando. La qarachupa advirtió que el otorongo (el jaguar) acabaría con los que ya había pescado $\mathrm{y}$, temiendo por su vida, le sugirió a su compañero que también él pescase algunos shitaris. El felino trató de hacerlo, pero no podía pescar porque flotaba demasiado, y no podía afirmar sus patas en el fondo del río. La carachupa le dio la solución diciendo: "tío, voy a buscar una soga en el monte para amarrarte dos piedras en el pescuezo y puedas así bucear en el río y agarrar shitaris". El jaguar cayó en el engaño, pero luego de enorme esfuerzo "con manotadas y sacudones logró romper la soga y liberarse". Muy enojado salió del río y persiguió al burlador, que rápidamente se trepó a un árbol llevando una piedra grande y cuatro shitaris. Cuando el felino llegó junto al tronco, la qarachupa le dijo "no me comas, tío tigre, te voy a dar estos cuatro shitaris, abre tu boca y cierra los ojos". Así lo hizo el perseguidor, y desde lo alto le cayó la piedra que le rompió los dientes. Una vez reanimado, el jaguar volvió a perseguir a la qarachupa, y cuando ya estaba próximo a alcanzarlo, nuestro personaje se detuvo y le dijo: "Espera tiíto, quiero leerte esta carta [simulando leer una hoja en blanco, hecha de corteza del árbol llamado cético]. Amigo qarachupa: Te escribo para avisarte que en este momento va a haber un diluvio para todos los tigres". Muy asustado, el jaguar siguió las indicaciones de la qarachupa que le aconsejó que se trepase a un árbol seco. A continuación, el taimado marsupial gritando "Tío, ya viene el diluvio" encendió el árbol y el fuego consumió a su ingenuo rival (Arguedas e Izquierdo 1970: 234-235).

Esta relación con la noche acerca nuestro personaje a los seres nocturnos más temidos del imaginario andino: los gentiles. Con ese nombre fueron calificados por la evangelización todos los antepasados de los indígenas que habían muerto sin las aguas del bautismo, y, por supuesto, quienes fallecían ignorando la prédica de los misioneros. El término mantiene su uso y ya que se presume que todos los peruanos son cristianos, se aplica especialmente a los restos óseos que se encuentran próximos en el interior de restos monumentales precolombinos.

Del universo de relatos que circulan en torno a los gentiles, cuya presencia atemoriza de muchas maneras a quienes habitan o transitan por sus dominios, existen aquellos que los vinculan con nuestro personaje. A pesar de su peligrosidad, los gentiles "ven" con envidia y nostalgia a los seres humanos. No son pocas las veces en que procuran disimular su apariencia descarnada, para asomar al mundo de los seres vivientes. 
La tradición que traemos a la memoria fue recogida en la localidad de Marcavalle (distrito de Pucará, provincia de Huancayo, departamento de Junín). En el cerro Rumicruz (Cruz de Piedra) que domina el pueblo se encuentran los remanentes de lo que fueran edificios precolombinos. El gentil que residía en esas ruinas añoraba los tiempos en que participaba de las fiestas que se celebraban en Marcavalle y al llegar la noche, premunido de algunas ropas que apenas cubrían sus brazos y piernas, pero envuelto en una bufanda y un poncho amplio y sombrero, bajaba a bailar cuando el alcohol y la música lo hacían pasar inadvertido. Antes de descender a Marcavalle el gentil pedía el apoyo de la qarachupa para que le avisase, poco antes del amanecer, para regresar al cerro. Cuando llegaba la hora, el animal buscaba al inquieto gentil, y lo jalaba del poncho para evitar la luz del día. Sucedió sin embargo que en el fragor de la fiesta y rodeado de damas que lo incitaban a seguir bailando, el gentil ignoró los tirones de la qarachupa y fue sorprendido por el amanecer, quedando convertido en un montón de huesos (Jiménez Borja 1973:58).

La asociación de nuestro personaje con el universo sobrenatural va mucho más allá que esta anécdota, como en el caso del gallinazo, su tránsito de un extremo a otro de los espacios favorables o agresivos con el hombre lo lleva desde su relación con los gentiles a enfrentar al jaguar o, como en una tradición ya cristianizada, a ser quien ayudó a la Virgen María a arrear la burra cuando huía de la persecución de Herodes (Ibérico s/f 111).

Por otra parte es importante resaltar que el tlacuache sea el animal elegido para indicar, asociado a la idea de poste, la cuatripartición del universo creado para los seres humanos. En los Andes, en épocas tempranas como la denominada Formativo (3000 a.C. - 250 a.C.) es posible presentar como hipótesis dicha cuatripartición, pero el animal emblemático se supone ser un jaguar, aunque para los autores de la propuesta la identificación del animal no sea tan importante, porque lo que realmente está en juego es un análisis que sea capaz de extraer la relación invariable de la combinación de elementos que presenta la iconografía, o en nuestro caso, los relatos orales (Watanabe 2013: 17 y 37).

La vigencia del modelo cuatripartito en el tiempo está todavía en proceso de demostración, pero no en vano el imperio incaico se llamó Tahuantinsuyo o las cuatro partes el mundo, lo que podría ser ya un indicio de lo perdurable de tales estructuras de pensamiento.

\section{La piel del jaguar o la escritura de Dios}

Si dedicamos ahora nuestra atención al tercero de nuestros personajes, cabe decir que por mucho tiempo fue el tema eje de la comparación entre andinos y mesoamericanos La presencia de imágenes felinas en el arte olmeca (cuyo centro geográfico fuera el sur de Veracruz y Tabasco) y las de Chavín (distrito de Chavín de Huantar, provincia de Huari, Ancash) han dado lugar a un largo debate que involucró hasta las vías de contacto entre ambos subcontinentes. Sin entrar en esa discusión, conviene reconocer que a pesar de que el jaguar no es el único de los felinos que existe en Mesoamérica, una "revisión de los estilos artísticos mayas y mexicanos mostrarán que el felino representado es casi exclusivamente el jaguar, con pocas representaciones del puma, lo mismo es cierto en el arte olmeca. De igual manera, una mirada al imaginario verbal de Mesoamérica nos indica que de manera abrumadora el jaguar concentra el interés de los mayas que lo llaman balam y entre los aztecas donde recibe el nombre de océlotl (Coe 1972: 2-3).

El mismo autor enfatiza la relación entre las visiones shamánicas inducidas por plantas alucinógenas y la construcción de la religión, que en algún momento hacia 1200 a.C. evolucionó desde la relación shaman-jaguar hacia una diferente en la que el lazo se forjaba entre el gobernante hereditario y el jaguar. Es así como el punto principal de la teogonía mesoamericana fue confirmar el poder real (op cit. 5 y 11).

Mil años después los mayas (de las tierras bajas), a quienes se considera herederos de los olmecas, siguieron construyendo pirámides pero "inventaron una nueva forma de usar la pirámidetemplo: la hicieron portadora de mensajes políticos, añadiendo tanto a la pirámide inferior como al templo superior fachadas del templo moldeadas y pintadas detalladamente. Estos grandes programas escultóricos se convirtieron en la expresión primaria de las doctrinas políticas y religiosas subyacentes a su forma de realeza (Schele y Freidel 2011: 123). No es extraño entonces que sean jaguares las máscaras en el centro de cada uno de los cuatro paneles del templo 1 ubicado en Cerros (distrito de Corozal, Bélice). La figura del jaguar se repite en otras partes de la estructura (op. cit. 143). 
Estas representaciones arquitectónicas o plásticas del jaguar expresan en formas visibles lo que recogería más tarde el Popol Vuh, al reconocer que "los primeros hombres creados, de quienes descienden los quichés, son jaguares y los gobernantes que les sucedieron conservan rasgos del animal e incluso se transforman en él..." (Valverde 2013: 302). Siguiendo con este razonamiento, la autora considera que "estos hombres fueron elegidos para fundar las dinastías gobernantes precisamente por su naturaleza felina, y desde entonces, desde los tiempos del origen, el felino aparece relacionado, en distintos niveles, con el grupo dirigente de los diversos pueblos, cuyos antepasados eran jaguares (Valverde 2013: 303).

No es extraño entonces que mayas e incas hayan asumido como nombre propio el de su ser emblemático. Así tenemos a Gran Garra Jaguar, el rey de Tikal que en el año 378 d.C. triunfó sobre Uaxatun (Schele y Freidel 2011: 169-189), y a Otorongo Achachi como el líder guerrero de las huestes incaicas en el intento de conquistar la Amazonía (Santa Cruz Pachacuti 1993: 232-236; Guamán Poma 1980: I, 65 y 133).

Lo dicho nos permite ingresar al terreno del otorongo (uturunqu en quechua) o Panthera onca del área andina. Las noticias sobre Otorongo Achachi (achachi o achachin son expresiones de miedo en el quechua de Ancash y Cajamarca) provienen de dos cronistas indígenas que nos muestran las dificultades del estado cuzqueño de lidiar con los pueblos al este de la cordillera.

No fue esta una empresa afortunada, si bien los pueblos andinos situados al borde del bosque tropical tuvieron y tienen frecuente contacto con los amazónicos, para el estado cuzqueño la gobernabilidad fue problemática. Los amazónicos se concentraban en las confluencias, curvas o cabecera de los ríos, y cada cierto tiempo se mudaban (y no son pocos que todavía lo hacen) de acuerdo con el rendimiento de las tierras agrícolas, que son de escasa continuidad fértil y tienen la necesidad de recesos prolongados. Otros factores azarosos son la caza y la recolección. Los incas necesitaban mano de obra con cierto nivel de organización a partir de un número considerable de futuros trabajadores, ubicados en espacios manejables para su administración. Además, el clima y el territorio les daban ventaja a quienes defendían su forma de vida, cuya riqueza cultural y manejo del medio geográfico eran muy ajenos a lo que proponían los invasores de las alturas andinas.
Otorongo Achachi es un personaje real o imaginario que explica en su biografía lo contradictorio que resultaba un amazónico en el pensamiento de los señores del Cuzco. Debido a que fue encargado de la conquista de los chunchos (nativo de la selva amazónica, por extensión: salvaje), tomó el nombre de Otorongo, a pesar de que era hijo del sexto gobernante: Inca Roca. Durante su campaña tuvo como esposa "a una yndia chunchu" (Guaman Poma 1980: I, 133) de la que tuvo un hijo, que junto con el guerrero se convirtieron en otorongos. Esta crónica del fracaso está narrada de distinta manera en otra fuente: Otorongo Achachi es el general de trescientos mil hombres y se le envía por una serie de lugares de identificación imprecisa en dirección a Carabaya (hoy es el nombre de una de las trece provincias del departamento de Puno), espacio que combina ecologías tan diversas como las de la sierra, ceja de selva y selva tropical (cálida y lluviosa, templada, frígida y seca, son los climas de la región). La expedición a Carabaya, en el lenguaje de las crónicas, más que un lugar determinado explica los inconvenientes que debió encontrar Otorongo Achachi. Además la zona es conocida por los kallawaya, etnia que desde hace tiempo es conocida por sus maestros curanderos.

El cronista a que recurrimos ahora también nos habla del fracaso del jefe militar y de su reemplazo, explicando que en su campaña había quedado manco. Lo que se entiende porque sus rivales amazónicos (a los que llama el reino de Esca y Oya) es "gente della mucha mas belicossa que quantas nacionas de por acá, los quales dizen que se sustenta con carne humana. Y de lo que es de echar ponssoñas y venenossas, saben como gente que tienen pactos con los demonios y son grandes flecheros" (Santa Cruz Pachacuti 1993: 337-338).

Con esta percepción, el jaguar difícilmente podía alcanzar el carácter emblemático que tuvo en Mesoamérica. Fue el puma, cuyos espacios de habitación y tránsito le eran familiares, y su piel sin manchas no causaba el recuerdo de la selva amazónica.

Sus formas se descubren en la iconografía sagrada mucho antes de los incas. En el monumento más importante de la sociedad Tiwanaku, la Puerta del Sol (3.842 metros de altitud, al sur del lago Titicaca), se ofrece un personaje central sobre el espacio que da sentido de puerta al edificio. Dicho personaje de forma humanoide muestra seis cabezas de puma insertas en su cuerpo. A los 
costados de la figura central están esculpidos tres tipos de personajes de perfil, como rindiéndole pleitesía. También algunas de estas figuras llevan en su atuendo cabezas de puma. Estas imágenes y muchas otras más inculcarían al puma con los símbolos de grandeza alrededor de 800 d.C., lejos del surgimiento del Cuzco (Watanabe 2013: 100-103).

En todo caso, no hay duda de que el puma (Puma concolor) es el símbolo de la dinastía que gobernó el Cuzco. La fundación del Tahuantinsuyo como estado imperial está muy bien descrita en los documentos que se recogieron de los nobles incaicos que quedaron al servicio de España. El héroe cultural Pachacuti, todavía con el nombre de Inca Yupanqui, había sido desplazado (igual que otros hijos del Inca reinante) por Urco, elegido por Viracocha como su sucesor. El reino del Cuzco debió ser para esa época (circa 1450) uno de los varios estados de la sierra sur-central peruana. La historia oficial continúa con la amenaza de la invasión de los chancas, antes sometidos por los incas, que se sublevan avanzando desde la sierra central, si es que aceptamos que su lugar de origen o pacarina (del quechua paqariy $=$ amanecer) fue la laguna de Choclococha (distritos de Santa Ana y Pilpichaca, provincias de Castrovirreina y Huaytará, departamento de Huancavelica). El Inca Viracocha y su heredero huyeron del Cuzco, lo que propició la decisión del joven Inca Yupanqui de defenderlo con la ayuda de una visión que lo deslumbra en la laguna de Sursunpuquio. Se le apareció el dios Sol con figura humana, estaba acompañado con emblemas que indicaban el futuro rol del puma. La cabeza del animal asomaba entre las piernas de la divinidad y su espalda estaba cubierta por la piel del felino. La visión le aseguró el triunfo y para ello lo ayudarían las piedras convertidas en guerreros que le darán la victoria (Molina 2010: 43).

Lo interesante del relato es que los propios chancas "jáctanse [de] descender del león [puma], y así le tenían y adoraban por dios y en sus grandes fiestas... sacaban dos docenas de indios de la misma manera que pintan a Hércoles, cubierto con pellejo de león, y la cabeza del indio metida en la cabeza del león. Yo la vi así en las fiestas del Santísimo Sacramento, en el Cuzco" (Garcilaso 1985: I,195). Vista así la imagen del puma, no es solo incaica, una vez organizado el imperio, Pachacutec Inca no hace sino legalizar como símbolo del Estado a un emblema que ya estaba generalizado en las sociedades de las alturas andinas. Prueba de ello es que las familias nobles de las mitades ceremoniales en que se dividía el Cuzco: Hanan y Hurin Cuzco "ya tenían aparejados unos leones desollados y las cabezas vacías, tenían puestas unas patenas de oro, y en lugar de dientes, que los habían sacado, les ponían dientes de oro y en las manos unas ajorcas de oro" (Molina 2010: 77-78). Ese era el vestido ceremonial para las danzas Taki coyo y Taki guallina, que eran parte de los festivales que celebraban la condición de adultos que alcanzaban los jóvenes nobles. Estamos en el polo opuesto de la percepción del jaguar.

\section{Reflexiones finales}

No es posible evitar que asociemos algunas características semejantes de los seres seleccionados en este ensayo, que surgen de las tradiciones que hemos relatado. Si como dice Tedlock, el animal que acude en socorro de los gemelos heroicos es el tlacuache, y oscurece el alba para salvar a uno de ellos, la muca andina intenta hacer lo mismo para ayudar al gentil, actuando como guardián del amanecer. También podemos recordar que pese a su sombrío prestigio, el zopilote logra robar la Luna, esposa del Sol, que se va a vivir con él. Causa no menos sorpresa que el gallinazo alcance a lucirse en el cielo como una de las constelaciones de las Pléyades, por encima de las menciones poco amables que aparecen en los relatos populares andinos.

Finalmente, a diferencia de los animales mencionados, andinos o mesoamericanos, es notoria la abierta contradicción entre el aura de cazador y guerrero que ostenta el jaguar, y la sombría fama del otorongo andino, rodeado de hechiceros, y habitante por excelencia de una tierra de salvajes embrujados, animales extraños, y plantas venenosas. El encumbramiento del puma, que huye de la presencia del hombre, parece apoyarse en el esfuerzo denigratorio del otorongo, situación que se hace difícil entender en Mesoamérica. Pero resulta lógico en los Andes, porque el jaguar es la cara visible de un lugar aterrador, habitado por gentes hostiles a los incas.

Es posible que sus cronistas hispanos o indígenas hispanizados no tuvieran la paciencia de aquel guerrero azteca, sepultado en prisión por Pedro de Alvarado. Sobre él nos evoca Borges, que luego de meditar hasta el éxtasis, entendió que en la piel del felino, dice el poeta, estaba escrito el mensaje de Dios. 


\section{Referencias Citadas}

Alva Meneses, Ignacio Ventarrón y Collud

2012 Origen y auge de la civilización en la costa norte del Perú. Lima: Ministerio de Cultura.

Anónimo Popol Vuh

2009 (Traducción al español de Antonio Recinos). Las antiguas historias del Quiché. México D.F.: Fondo de Cultura Económica.

Anónimo Popol Vuh

1985 (Traducción al inglés de Dennis Tedlock). The Mayan Book of de Dawn of Life. New York: Simon y Schuster.

Arguedas, José María y Francisco Izquierdo

1970 Mitos, leyendas y cuentos peruanos. Lima: Casa de la Cultura.

Ávila, Francisco de

2007 [compilador] Dioses y hombres de Huarochirí. Traducción de José María Arguedas. Estudio introductorio de Luis Millones y Hiroyasu Tomoeda. Lima: Universidad Ruiz de Montoya.

Coe, Michael D.

2013 Olmec Jaguars and Olmec Kings. En: Elizabeth P. Benson (Editor). The Cult of the Feline. Washington D.C.: Dumbarton Oaks Research Library and Collections, 1972.

Craveri, Michela E.

Popol Vuh. Herramientas para una lectura crítica del texto k'iché, traducción al español, notas gramaticales y vocabulario... México D.F.: Centro de Estudios Mayas. UNAM.

Charbonneau-Lassay, L.

1997 El bestiario de Cristo. Simbolismo animal en la Antigüedad y la Edad Media. Barcelona: Sophia Perennis.

Donnan, Christopher B.

1978 Moche Art of Perú. Los Angeles: Museum of Natural History.

Donnan, Christopher B. y Guillermo Cock (Editores)

1986 The Pacatnamu Papers. Volume I. Introducción de C.B. Donnan. Los Angeles: Museum of Natural History.

Garcilaso de La Vega

1985 INCA Comentarios Reales de los Incas. Caracas: Biblioteca Ayacucho.

Galinier, Jacques

1990 La mitad del mundo. Cuerpo y cosmos de los rituales otomíes. México D.F.: Instituto Indigenista y Centro de Estudios Mexicanos y Centroamericanos. UNAM.

González Holguín, Diego

1989 Vocabulario de la lengua general de todo el Perú llamada Lengua quichua o del Inca. Lima: Universidad Nacional Mayor de San Marcos.

Guaman Poma de Ayala, Phelipe

1980 Nueva Corónica y Buen Gobierno. México D.F. Siglo Veintiuno Editores.
Ibérico Mas, Luis

El folklore de Cajamarca. n.d.

Jiménez Borja, Arturo

1973 Imagen del mundo aborigen. Lima: Editorial Jurídica S.A.

Landa, Diego de

2002 Relación de las cosas de Yucatán. Madrid: Dustin S.L.

Limón, Silvia y Clementina Battcock

2013 Aves solares: el águila, el colibrí y el zopilote. En: Luis Millones y Alfredo López Austin (Editores). Fauna fantástica de Mesoamérica y los Andes. México D.F.:UNAM.

López Austin, Alfredo

1990 Los mitos del tlacuache. México D.F.: Alianza Editorial Mexicana.

López Austin, Alfredo y Luis Millones

2008 Dioses del Norte, Dioses del Sur. Religiones y cosmovisión de Mesoamérica y los Andes. México D.F.: Ediciones Era.

Molina, Cristóbal de

2010 Relación de las fábulas y mitos de los incas. Edición crítica de Paloma Jiménez del Campo. Madrid: Iberoamericana.

Núñez Jiménez, Antonio

1986 Petroglifos del Perú. La Habana: Editorial Científico-Técnica.

Pizarro, Pedro

1978 Relación del descubrimiento y conquista de los reinos del Perú. Lima: Pontificia Universidad Católica.

Rea, Amadeo M.

1986 Black Vultures and Human Victims: Archaelogical Evidence from Pacatnamu. En: Donnan, Christopher B. y Guillermo Cock (Editores). Pacatnamu Papers. Volume I. Los Angeles: Museum of Natural History.

Santa Cruz Pachacuti, Joan

1993 Relación de antiguedades deste reyno del Pirú. Cuzco: IFEA y Centro "Las Casas".

Schele, Linda y David Freidel

2011 Una selva de reyes. La asombrosa historia de los antiguos mayas. México D.F.: Fondo de Cultura Económica.

Valverde Valdés, María del Carmen

2013 Imágenes del jaguar en la plástica maya. Aproximación a una lectura simbólica. En: Luis Millones y Alfredo López Austin. Fauna fantástica en Mesoamérica y los Andes. México D.F.: Instituto de Investigaciones Antropológicas, UNAM.

Watanabe, Shinya

2013 Estructura de los andes antiguos. Yokohama: Editorial Shumpusha. 